\title{
Linalool inhibits the growth of human $T$ cell acute lymphoblastic leukemia cells with involvement of the MAPK signaling pathway
}

\author{
XUBO GONG ${ }^{1}$, BAIYONG WANG $^{2}$, LIJUAN YAN $^{3}$, XIAOYA $^{4}{ }^{4}$ and XIAOYING ZHAO ${ }^{4}$ \\ ${ }^{1}$ Department of Clinical Laboratory, The Second Affiliated Hospital, School of Medicine, Zhejiang University; \\ ${ }^{2}$ Department of Intensive Care Unit, The First Hospital of Hangzhou Normal University; Departments of ${ }^{3}$ Nephrology and \\ ${ }^{4}$ Hematology, The Second Affiliated Hospital, School of Medicine, Zhejiang University, Hangzhou, Zheijang 310000, P.R. China
}

Received October 2, 2019; Accepted July 16, 2020

DOI: $10.3892 / \mathrm{ol} .2020 .12042$

\begin{abstract}
Linalool can inhibit the malignant proliferation of numerous human malignant solid tumors, including hepatocellular carcinoma, breast cancer, small cell carcinoma and malignant melanoma. However, the role of linalool in $\mathrm{T}$ cell acute lymphoblastic leukaemia (T-ALL) remains unclear. In the present study, human T-ALL cell lines (Jurkat, H9, Molt-4 and Raji cells) and peripheral blood mononuclear cells (PBMCs) from healthy donors were treated with various concentrations of linalool $(3.75,7.50,15.00,30.00,60.00$ and $120.00 \mu \mathrm{M}$, respectively). A CCK-8 assay was used to analyse cell viability and it demonstrated that linalool inhibited the growth of T-ALL cells in a dose-dependent manner, but did not significantly affect normal PBMCs. Flow cytometry was used to detect the cell cycle and apoptosis and demonstrated that linalool reduced the percentage of T-ALL cells at the $\mathrm{G}_{0} / \mathrm{G}_{1}$ phase, and induced the apoptosis of T-ALL cells. RNA sequencing was conducted on an Illumina HiSeq X Series 2500 before and after treatment with linalool followed by Gene Ontology and Kyoto Encyclopedia of Genes and Genomes pathway enrichment analysis. It was demonstrated that the mitogen-activated protein kinase (MAPK) pathway was involved in the effect of linalool on T-ALL cells. Real-time quantitative PCR and western blotting were performed to verify the mRNA and protein levels, respectively of the genes in the signaling pathway identified. In addition, it was found that linalool significantly inhibited phosphorylated (p)-ERK1/2 protein expression and enhanced $\mathrm{p}-\mathrm{JNK}$ protein expression of T-ALL cells. In conclusion, the present study revealed that linalool inhibits T-ALL cell survival with involvement of the MAPK signaling pathway. JNK activation and ERK inhibition
\end{abstract}

Correspondence to: Dr Xiaoying Zhao, Department of Hematology, The Second Affiliated Hospital, School of Medicine, Zhejiang University, 88 Jiefang Road, Hangzhou, Zheijang 310000, P.R. China

E-mail: zrxz@zju.edu.cn

Key words: leukemia, mitogen-activated protein kinases, linalool, $\mathrm{T}$ cell may play a functional role in apoptosis induction of T-ALL cells. Linalool may be developed as a novel anti T-ALL agent.

\section{Introduction}

According to the 2017 WHO classification of tumors of hematopoietic and lymphoid tissues, $T$ cell acute lymphoblastic leukaemia (T-ALL) accounts for $25 \%$ of the cases of adult ALL and $\sim 15 \%$ of childhood ALL cases globally (1). Clinically, T-ALL typically presents with a high leukocyte count and frequently with a large mediastinal or gastrointestinal mass (1). Lymphadenopathy and hepatosplenomegaly are common (2). T-ALL compared with B cell acute lymphoblastic leukaemia often manifests with relative sparing of normal bone marrow hematopoiesis and is associated with a higher risk of induction failure, early relapse and isolated central nervous system relapse $(1,2)$. Although, the use of combination chemotherapy regimens, including vincristine, daunorubicin, and prednisolone has gradually improved the clinical outcome of T-ALL over the last few decades, majority of patients with T-ALL eventually relapse $(3,4)$. Allogenetic hematopoietic stem cell transplantation may be the only potential curative therapy (5) and is also essential to identify novel agents suitable for elderly and weak patients with T-ALL.

Linalool, a natural small molecular compound is isolated from various oils, such as camphor leaf oil, galoin oil and rosewood oil (6). Linalool is a colorless liquid that can be mixed with ethanol and ether and is insoluble in water and glycerol (7). Currently, linalool is mainly used as an antimicrobial and antiviral agent, perfume, deodorant, anticaries agent and insecticide $(8,9)$. In recent years, it has been proven that linalool can inhibit the malignant proliferation of numerous human malignant solid tumors, including hepatocellular carcinoma, breast cancer, small cell carcinoma, and malignant melanoma (10-13). Linalool has also been demonstrated to have antiproliferative activity against some hematological diseases, including chronic myelogenous leukaemia, acute promyelocytic leukaemia and Burkitt's lymphoma (14-19). However, the effect of linalool on T-ALL remains unclear.

Linalool is inexpensive and may be developed as a novel therapeutic agent for tumors (20). In the present study, in order to reveal the role of linalool on T-ALL the effects of linalool on T-ALL cell lines as well as peripheral blood 
mononuclear cells (PBMCs) from healthy donors were investigated.

\section{Materials and methods}

Agents and antibodies. Linalool (with purity $\geq 95 \%$ and molecular weight=154.25 Da) was purchased from Sigma-Aldrich; Merck KGaA (cat. no. 78-70-6) and its formula is provided in Fig. 1A. Linalool was dissolved in dimethyl sulfoxide (DMSO) and used at the required concentration $(30 \mu \mathrm{M}$ linalool was the most frequently used as it approached $50 \%$ inhibition at $48 \mathrm{~h}$ ). The final concentration of DMSO was $<0.1 \%$ in the RPMI-1640 culture medium (cat. no. 670089; Invitrogen; Thermo Fisher Scientific Inc.). Mouse antibodies against p38 (1:1,000; cat. no. sc-398305), p-p38 (1:1,000; cat. no. sc-166182), JNK (1:1,000; cat. no. sc-7345), p-JNK (1:1,000; cat. no. sc-6254), $\beta$-actin $(1: 1,000$; cat. no. sc-47778), poly (ADP-ribose) polymerase 1PARP-1 (1:1,000; cat. no. sc-8007), cleaved PARP-1 (1:1,000; cat. no. sc-56196), were purchased from Santa Cruz Biotechnology Inc. PD98059 (cat. no. 9900), SP600125 (cat. no. 8177), SB203580 (cat. no. 5633) and rabbit primary antibodies against ERK1/2 (1:1,000; cat. no. 4376), p-ERK1/2 (1:1,000; cat. no. 4370), Growth Arrest And DNA Damage Inducible $\alpha$ (GADD45A) (1:1,000; cat. no. 4632S), caspase-3 (1:1,000; cat. no. 9662), cleaved caspase-3 (1:1,000; cat. no. 9664) and secondary antibodies (1:1,000; cat. nos. 7074 and 7076) were purchased from Cell Signaling Technology Inc.

Cell lines and cell culture. Human T-ALL cell lines (Jurkat, H9, Molt-4 and Raji) were obtained from Zhejiang University (Hangzhou, China). The cells were cultured in RPMI-1640 medium (Invitrogen; Thermo Fisher Scientific Inc.) supplemented with $10 \%$ fetal calf serum (FCS; Invitrogen; Thermo Fisher Scientific Inc.), $2 \mathrm{mmol} / 1$ glutamine, $0.1 \mathrm{mg} / \mathrm{ml}$ streptomycin, and $100 \mathrm{U} / \mathrm{ml}$ penicillin and incubated at $37^{\circ} \mathrm{C}$ in a $5 \% \mathrm{CO}_{2}$ humidified incubator. All experiments using these cell lines were performed within 6 months of receipt or thawing after $-80^{\circ} \mathrm{C}$ cryopreservation, the cells were passaged every 2 days with fresh medium. In all experiments, cells were used in logarithmic growth phase. As a normal cell line was not available, PBMCs were chosen for comparison in the present study. PBMCs were collected from healthy donors after informed written consent was obtained $(n=7,4$ males and 3 females; age range, 25.5-34.2 years, with the median age of 27.4 years). All were from the Second Affiliated Hospital, School of Medicine, Zhejiang University (Hangzhou, China), and $2 \mathrm{ml}$ of blood was obtained each donor. PBMCs were isolated with Ficoll-Hypaque gradients by centrifugation from fresh blood (19). This study was approved by the Ethics Committee of The Second Affiliated Hospital, School of Medicine, Zhejiang University (Hangzhou, China) (approval number, IR2020001187) according to the guidelines of the Declaration of Helsinki.

Cell viability assay. Cell viability was measured using the Cell Counting Kit-8 (CCK-8) reagent (Donjindo Molecular Technologies, Inc.) according to the manufacturer's protocol, the OD value was used for measuring absorbance (21). Briefly, one experiment was performed to investigate the effect of linalool on T-ALL viability, human T-ALL cell lines (Jurkat, H9, Molt-4, and Raji cells) and normal PBMCs were cultured in 96-well plates $\left(2 \times 10^{5}\right.$ cells $\left./ \mathrm{ml}\right)$, and then linalool $(3.75,7.50$, $15.00,30.00,60.00$ and $120.00 \mu \mathrm{M}$, respectively) was added to the cells. Another experiment was performed to investigate the effect of linalool and ERK1/2-selective inhibitor PD98059, JNK inhibitor SP600125 or P38 inhibitor SB203580 on T-ALL viability, Jurkat cells were cultured in 96-well plates ( $2 \times 10^{5}$ cells $\left./ \mathrm{ml}\right)$, and $10 \mu \mathrm{mol} / 1 \mathrm{ERK} 1 / 2$-selective inhibitor PD98059, $20 \mu \mathrm{mol} / 1 \mathrm{JNK}$ inhibitor SP600125 or $10 \mu \mathrm{mol} / 1 \mathrm{P} 38$ inhibitor SB203580 was added to the cell suspensions for $1 \mathrm{~h}$. Subsequently, $30 \mu \mathrm{M}$ linalool was added to the cell suspensions for $9 \mathrm{~h}$. The cells were then harvested and measured by the CCK- 8 assay. The control group consisted of cells treated with DMSO only.

Cell cycle analysis. Flow cytometry (FCM) was performed to determine the effect of linalool on the cell cycle following a standard protocol $(21,22)$. Briefly, Jurkat cells $\left(2 \times 10^{5}\right.$ cells $\left./ \mathrm{ml}\right)$ were treated with $30 \mu \mathrm{M}$ linalool for $6,12,24$ or $48 \mathrm{~h}$ at $37^{\circ} \mathrm{C}$. The cells were washed and fixed in $70 \%$ ice-cold ethanol overnight at $4^{\circ} \mathrm{C}$. Subsequently, the cells were harvested and incubated in PBS with $100 \mathrm{mg} / \mathrm{ml}$ propidium iodide (PI), $0.1 \%$ Triton X-100 for permeabilization and $100 \mu \mathrm{g} / \mathrm{ml}$ RNase A for $30 \mathrm{~min}$ at $4^{\circ} \mathrm{C}$ (Beyotime Institute of Biotechnology). The PI-stained cells were subjected to cell cycle profiling analysis using a flow cytometer (FACSCalibur; BD Biosciences). The cell cycle distribution was analysed using ModFit LT software version 3.1 (Verity Software House, Inc.).

Apoptosis assay. Apoptosis was investigated using an Annexin V-fluorescein isothiocyanate (FITC) apoptosis kit (cat. no. K101; BioVision, Inc.) according to the manufacturer's instructions $(21,22)$. Briefly, in one experiment, Jurkat cells were treated with $30 \mu \mathrm{M}$ linalool for 6,12 or $24 \mathrm{~h}$ at $37^{\circ} \mathrm{C}$, respectively. In another experiment, Jurkat cells were pre-treated with $10 \mu \mathrm{mol} / 1$ PD98059, $20 \mu \mathrm{mol} / 1$ SP600125, or $10 \mu \mathrm{mol} / 1 \mathrm{SB} 203580$ for $1 \mathrm{~h}$ and then $30 \mu \mathrm{M}$ linalool was added to the cells suspensions for $9 \mathrm{~h}$ at $37^{\circ} \mathrm{C}$. The cells were harvested and washed with ice-cold PBS 3 times and adjusted to $1 \times 10^{6}$ cells $/ \mathrm{ml}$ with binding buffer. Subsequently, the cells were incubated with $5 \mu \mathrm{l}$ FITC-labelled Annexin V and $5 \mu \mathrm{l}$ PI at room temperature in the dark for $15 \mathrm{~min}$. Finally, the stained cells were analysed using a flow cytometer (FACSCalibur, BD Biosciences). The data were analysed using FlowJo software version 10.0.7 (Tree Star, Inc.). The control group was DMSO only.

Morphological analysis. Jurkat cells $\left(2 \times 10^{5}\right.$ cells $\left./ \mathrm{ml}\right)$ were cultured with $30 \mu \mathrm{M}$ linalool for various time periods $(0,6,12$ or $24 \mathrm{~h})$. Cytospin slides $(4-8 \mu \mathrm{m})$ were prepared, cells were fixed with $100 \%$ methanol at room temperature for $1 \mathrm{~min}$, and stained with Wright-Giemsa staining (Baso Diagnostics Inc.) for $10 \mathrm{~min}$ at room temperature. Cell morphology was observed with a light microscope (Olympus Corporation, magnification $\mathrm{x} 1,000)$.

RNA extraction, cDNA library construction and Illumina sequencing. Jurkat cells $2 \times 10^{5}$ cells $/ \mathrm{ml}$ ) were treated with $30 \mu \mathrm{M}$ linalool for $9 \mathrm{~h}$ and then total RNA from Jurkat cells 
A

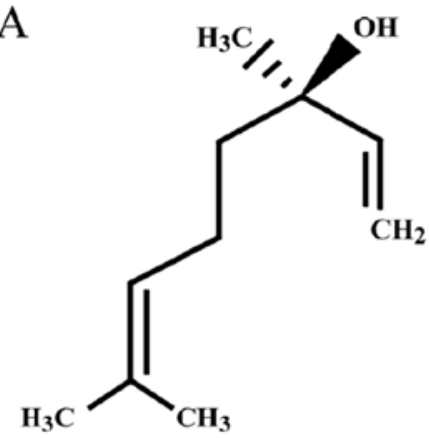

B

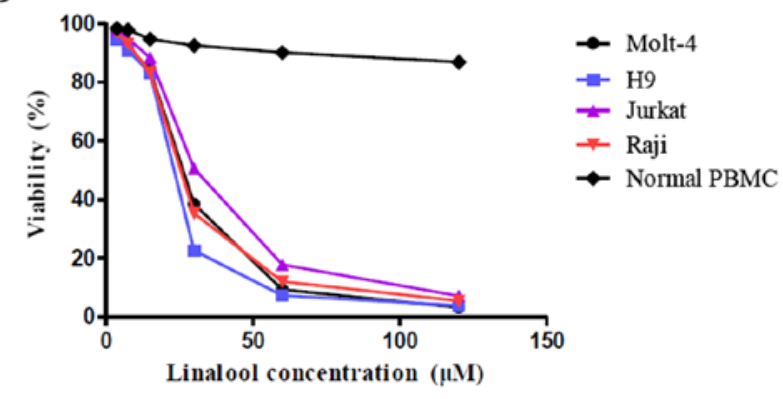

C Control

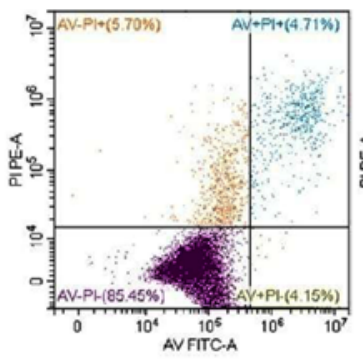

D

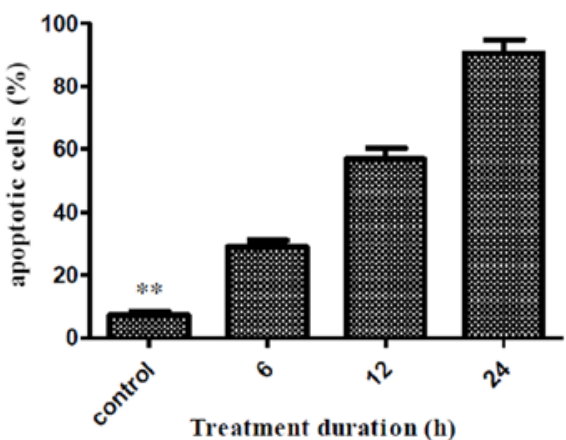

$12 \mathrm{~h}$

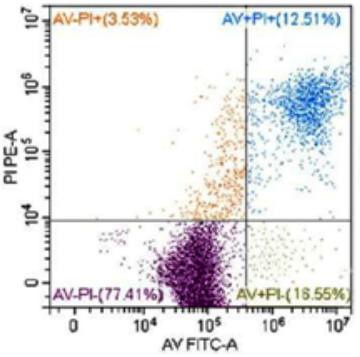

$6 \mathrm{~h}$

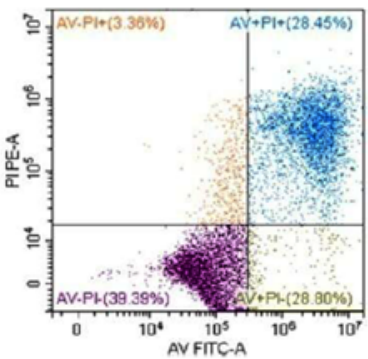

$\mathrm{E}$
$24 \mathrm{~h}$

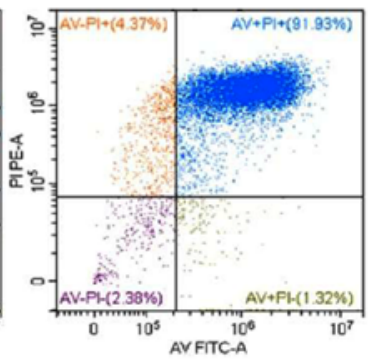

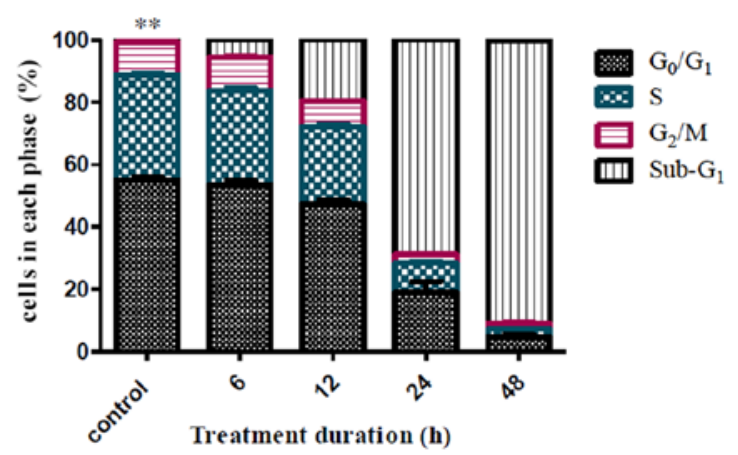

F Control

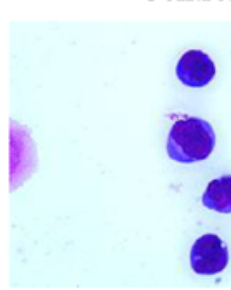

$6 \mathrm{~h}$

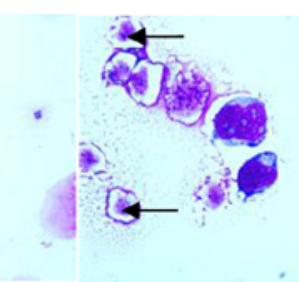

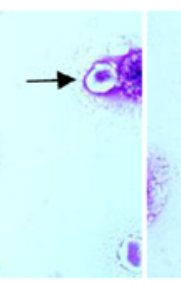

$12 \mathrm{~h}$

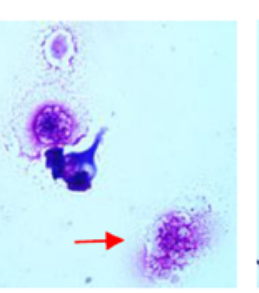

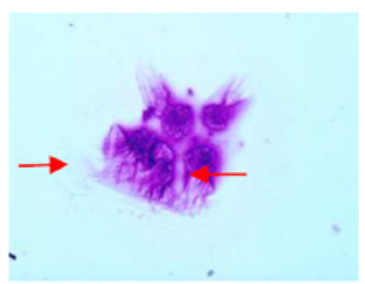

Figure 1. Effects of linalool treatment on T-ALL cells. (A) Molecular formula of linalool. (B) Linalool inhibited the growth of Jurkat, H9, Molt-4 and Raji cells in a dose-dependent manner, but it had almost no effects on the viability of normal PBMCs. (C and D) Jurkat cells were treated with $30 \mu \mathrm{M}$ linalool for 6, 12 or $24 \mathrm{~h}$, respectively. The percentage of apoptotic cells was significantly increased in a time-dependent manner compared with the control group (treatment with DMSO only), ${ }^{* *} \mathrm{P}<0.01$. (E) Treatment of Jurkat cells with $30 \mu \mathrm{M}$ linalool resulted in a significant decrease of $\mathrm{G}_{0} / \mathrm{G}_{1,} \mathrm{G}_{2}$, and $\mathrm{S}$ phase cells with a concomitant increase of sub- $\mathrm{G}_{1}$ phase cells compared with the control group (treatment with DMSO only), ${ }^{* *} \mathrm{P}<0.01$. (F) Jurkat cells were killed by $30 \mu \mathrm{M}$ linalool in a time-dependent manner, apoptotic bodies (black arrows) were present after $6 \mathrm{~h}$ treatment and apoptotic cellular debris (red arrows) were increased after $12 \mathrm{~h}$ treatment, and plenty of apoptotic cellular debris was found for $24 \mathrm{~h}$ (Wright-Giemsa staining; magnification x1000). All experiments were repeated at least three times. PI, propidium iodide; T-ALL, T cell acute lymphoblastic leukaemia; PBMCs, peripheral blood mononuclear cells.

before and after treatment with linalool was isolated using TRIzol reagent (Invitrogen; Thermo Fisher Scientific Inc.) for $5 \mathrm{~min}$ at $4^{\circ} \mathrm{C}$ according to the manufacturer's instructions. RNA integrity was evaluated using an Agilent Bioanalyser 2100 (Agilent Technologies, Inc.). Paired-end libraries were constructed with the TruSeq RNA Sample Preparation kit (Illumina Inc.; cat. no. RS-122-2001) following the TruSeq RNA Sample Preparation Guide. Briefly, polyadenylated RNA was isolated and fragmented into $200 \mathrm{bp}$ fragments. The first-strand cDNA was synthesized using random hexamer 
primers, and the second strand cDNA was synthesized using DNA Polymerase I and RNase $\mathrm{H}$, followed by an end repair process with the addition of a single 'A' base and ligation of the adapters. Library quality control was performed with 2100 Bioanalyzer (Agilent Technologies Inc.). The DNA library concentration was diluted to $10 \mathrm{nM}$ with hybridization buffer (Illumina Inc.) for library normalization. DNA sequencing was performed on the Illumina HiSeq 2500 platform. Synthesis sequencing was performed with the HiSeq Rapid SBS Kit v2 (cat. no. 402-4023; Illumina Inc.), generating single-fragment reads (2x150 bp; PE) with two fragment end-to-end assemblies. The DNA library was loaded into the flow cell and placed in a cBot device (Illumina, Inc.). The cycle sequencing procedure was performed with the HiSeq Rapid SBS Kit v2 according to the manufacturer's instructions. In brief, the libraries were bound to immobilized oligos on flow cells, DNA was synthesized through polymerase activity from the free $3^{\prime}$ end and cyclic bridge amplification, denaturation, linearization, $3^{\prime}$ end blocking, reverse strand denaturation and re-amplification procedures for clustering were performed. The FASTQ file obtained from the present study was analyzed on the web-based Galaxy platform (https://usegalaxy.org/).

Real-time quantitative PCR (RT-qPCR). Briefly, RNA was extracted from Jurkat cells with TRIzol reagent (Thermo Fisher Scientific Inc.) according to the manufacturer's protocol. cDNA was obtained by a High Capacity cDNA Archive kit (Applied Biosystems; Thermo Fisher Scientific Inc.). The reverse transcription reactions were as follows: $10 \mathrm{~min}$ at $25^{\circ} \mathrm{C}, 120 \mathrm{~min}$ at $37^{\circ} \mathrm{C}$ and $5 \mathrm{~min}$ at $85^{\circ} \mathrm{C}$. The samples were then placed on ice. The PCR solution was a master mix that included SYBR Green Mastermix (Beijing Solarbio Science \& Technology Co., Ltd.), forward primer, reverse primer and $10 \mathrm{ng}$ template cDNA. The final concentration of primers in the PCR solution was $0.45 \mu \mathrm{mol} / 1$. GADD45A and heat shock protein 27 (HSP27) sequences were amplified using the following gene-specific primers. GADD45A, forward, 5'-GAGAGCAGAAGACCGAAAGGA-3' and reverse, 5'-CAC AACACCACGTTATCGGG-3'; HSP27, forward, 5'-ACGGTC AAGACCAAGGATGG-3' and reverse, 5'-AGCGTGTATTTC CGCGTGA-3'; GAPDH, forward, 5'-TGACTTCAACAGCGA CACCCA-3' and reverse, 5'-CACCCTGTTGCTGTAGCC AAA-3') was used as an internal control to normalize the PCR results. The reaction was performed on a 7500 Real-Time PCR System (Applied Biosystems; Thermo Fisher Scientific Inc.). The amplification conditions for the assay were set as follows: Initial denaturation at $95^{\circ} \mathrm{C}$ for $10 \mathrm{~min}$, then 40 cycles of denaturation at $95^{\circ} \mathrm{C}$ for $10 \mathrm{sec}$ and annealing/extension at $60^{\circ} \mathrm{C}$ for $60 \mathrm{sec}$. The PCR results were analysed using the comparative $2^{-\Delta \Delta \mathrm{Cq}}$ method (23) using the AB Prism software (Applied Biosystems; Thermo Fisher Scientific Inc.).

Gene Ontology (GO) analysis and Kyoto Encyclopedia of Genes and Genomes (KEGG) pathway enrichment analysis. Clean reads of each developmental stage sample were mapped to transcriptome assembly results by Bowtie with a maximum mismatch set to 2 (22) and $<2$ mismatches were allowed in the alignment. The number of mapped clean reads for each UniGene was calculated and normalized to fragments per $\mathrm{kb}$ per million reads, which is a widely used method to calculate the levels of gene expression (24). GO analysis (25) and KEGG pathway (26) enrichment analysis of mRNA were performed with the R language version 3.4.4 cluster Profiler (27), org.Hs.eg. $\mathrm{db}$ genome-wide annotation (https://bioconductor.org/packages/org.Hs.eg.db/), the topGO package (https://bioconductor. org/packages/topGO/), the pathview R package (https://bioconductor.org/packages/pathview/) and the enrichplot package (https:/github.com/GuangchuangYu/enrichplot). The ggplot2 package (http://ggplot2.tidyverse.org) was used to create the graphics (28). Differentially expressed genes were identified with an absolute fold-change $\geq 2$ as the cut off value (29). Heatmap was performed with the R language version 3.4.4.

Western blotting. Jurkat cells $\left(2 \times 10^{5}\right.$ cells $\left./ \mathrm{ml}\right)$ were treated with $30 \mu \mathrm{M}$ linalool for $6 \mathrm{~h}, 12 \mathrm{~h}$ or $24 \mathrm{~h}$ at $37^{\circ} \mathrm{C}$, and then the cells were harvested and washed with ice-cold PBS 3 times. Proteins were extracted using lysis buffer (Beyotime Institute of Biotechnology) that contained protease inhibitors (Sigma-Aldrich; Merck KGaA) and a phosphatase Inhibitor Cocktail Set II (cat. no. 524625; Sigma-Aldrich; Merck KGaA; added each solution at 1:100 (v/v) dilution to cell lysates) was used in the lysis buffer for detection of phosphorylated proteins. Protein concentration was analysed with a bicinchoninic acid (BCA) protein assay kit (Beyotime Institute of Biotechnology). Total protein (40 $\mu \mathrm{g} /$ lane) was separated using $10-12 \%$ sodium dodecyl sulfate-polyacrylamide gel electrophoresis gels and transferred to a polyvinyl difluoride membrane (Bio-Rad Laboratories Inc.). The membrane was subsequently blocked with TBST $(0.05 \%$ Tween- 20$)$ containing $5 \%$ skimmed milk for $1 \mathrm{~h}$ at $4^{\circ} \mathrm{C}$ and probed overnight with the corresponding primary antibodies (ERK, p-ERK, GADD45A, cleaved PARP, caspase-3, cleaved caspase-3, JNK, p-JNK, P38, p-P38, and $\beta$-actin) at $4^{\circ} \mathrm{C}$. The membrane was washed and incubated with secondary antibodies (goat anti-rabbit $\mathrm{IgG}$, conjugated to horse-radish peroxidase) for $1 \mathrm{~h}$ at room temperature and then reacted with SuperSignal West Pico chemiluminescent substrate (Pierce; Thermo Fisher Scientific Inc.) for visualization (24). $\beta$-actin was used as the loading control. ImageJ software version 1.8.0 was used for densitometry analysis (National Institutes of Health).

Statistical analysis. Data are presented as the mean \pm SD of at least 3 biological replicates. Multiple group comparisons were performed using ANOVA followed by the post hoc Tukey's test and comparisons between two groups were performed using unpaired Student's t-test. $\mathrm{P}<0.05$ was considered to indicate a statistically significant difference. Statistical analysis was conducted using GraphPad Prism version 5.0 software (GraphPad Software, Inc.).

\section{Results}

Linalool inhibits the growth of T-ALL cells. A CCK-8 assay was used to analyse cell viability, it demonstrated that linalool inhibited the growth of Jurkat, H9, Molt-4 and Raji cells in a dose-dependent manner (Fig. 1B). The 50\% inhibition ( $\left.\mathrm{IC}_{50}\right)$ at $48 \mathrm{~h}$ was calculated using GraphPad Prism version 5.0 software and it demonstrated that the $\mathrm{IC}_{50}$ at $48 \mathrm{~h}$ of Jurkat, H9, Molt-4 and Raji cells was 31.35, 22.16, 25.80 and $25.19 \mu \mathrm{M}$, respectively (data not shown). In contrast, treatment with 


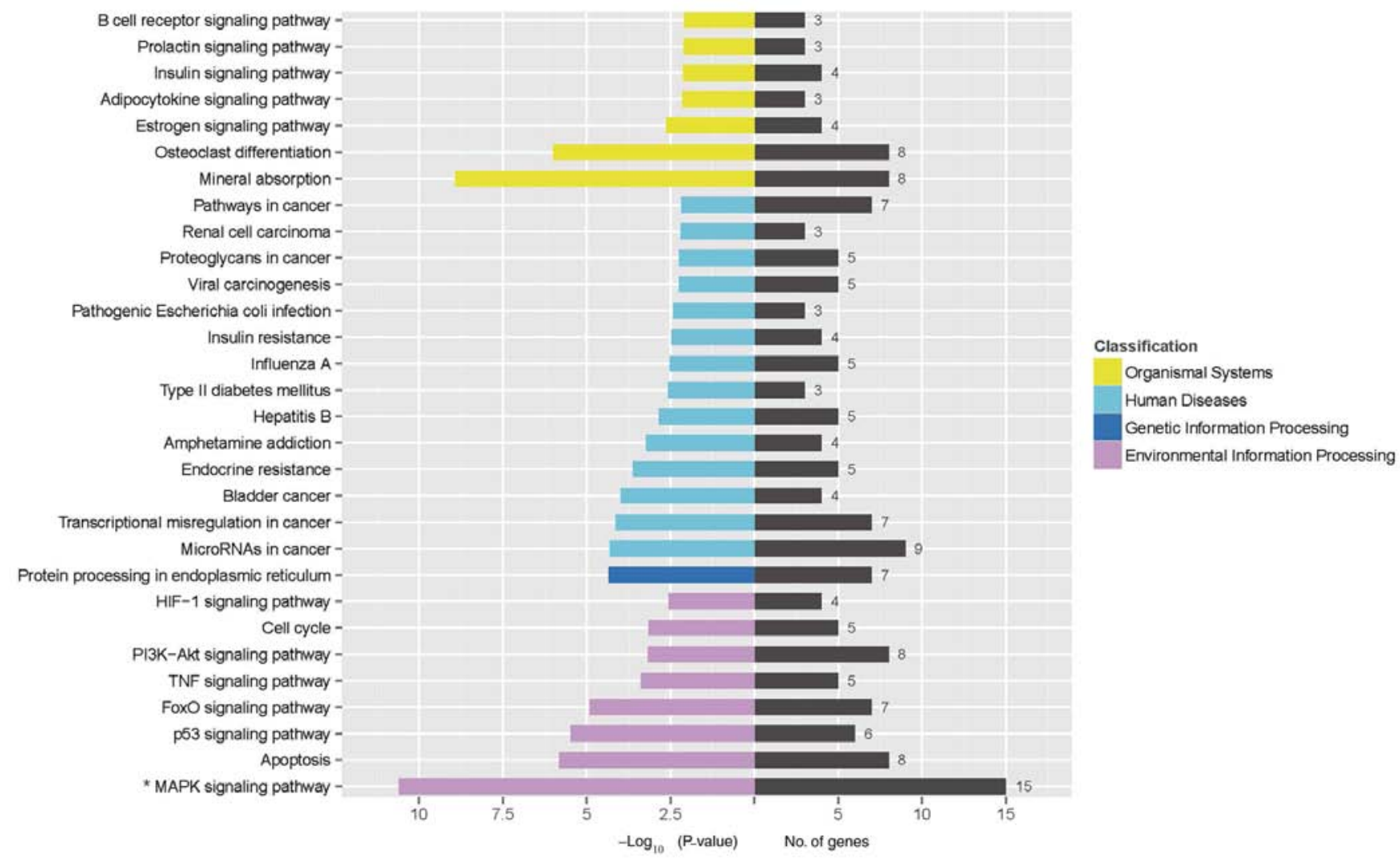

Figure 2. Linalool inhibited T-ALL cell survival with the involvement of the MAPK signaling pathway. Enrichment of mRNAs in the regulatory network was assessed via analysis of the Kyoto Encyclopedia of Genes and Genomes pathways and it was demonstrated that the MAPK signaling pathway is involved in the effect of linalool treatment of Jurkat cells. T-ALL, T cell acute lymphoblastic leukaemia. The experiment was repeated at least three times.

$30 \mu \mathrm{M}$ linalool had almost no effects on the viability of normal PBMCs, and there was a very slight decrease in the percentage of viable cells $(86.84 \pm 2.04 \%)$ after treatment with $120 \mu \mathrm{M}$ linalool (Fig. 1B).

Linalool induces apoptosis of T-ALL cells. Jurkat cells were treated with $30 \mu \mathrm{M}$ linalool for 6,12 or $24 \mathrm{~h}$, respectively. The percentage of apoptotic Jurkat cells increased in a time-dependent manner from $28.92 \pm 3.70 \%$ at $6 \mathrm{~h}$ to $56.92 \pm 5.92 \%$ at $12 \mathrm{~h}$ to $90.50 \pm 7.38 \%$ at $24 \mathrm{~h}$ (Fig. $1 \mathrm{C}$ and D). Significant differences were observed compared to the control group which had a percentage of apoptotic Jurkat cells of $7.34 \pm 1.89 \%$ (all $\mathrm{P}<0.01$; Fig. 1C and D). Wright-Giemsa staining demonstrated that Jurkat cells were killed after treatment with $30 \mu \mathrm{M}$ linalool in a time-dependent manner as apoptotic bodies (black arrows) were present after treatment with linalool for $6 \mathrm{~h}$ and apoptotic cellular debris (red arrows) was increased after treatment with linalool for $12 \mathrm{~h}$ and plenty of apoptotic cellular debris was found for $24 \mathrm{~h}$ (Fig. 1F).

Linalool reduces $T$-ALL cell accumulation at the $G_{0} / G_{I}$ phase. Following treatment of Jurkat cells with $30 \mu \mathrm{M}$ linalool, $\mathrm{G}_{0} / \mathrm{G}_{1}$, $\mathrm{S}$ and $\mathrm{G}_{2} / \mathrm{M}$ phase cells were significantly decreased in a time-dependent manner. After 48 h of treatment with linalool, the percentage of $\mathrm{G}_{0} / \mathrm{G}_{1}$ phase cells in the control group (DMSO treatment only) decreased from $55.02 \pm 1.54$ to $4.89 \pm 0.91 \%$, the percentage of $\mathrm{S}$ phase cells decreased from $33.68 \pm 1.13$ to $2.37 \pm 0.12 \%$ and the percentage of $\mathrm{G}_{2} / \mathrm{M}$ phase cells decreased from $10.51 \pm 0.57$ to $2.06 \pm 0.03 \%$ (all $\mathrm{P}<0.01$; Fig. $1 \mathrm{E}$ ). In contrast, the percentage of sub- $\mathrm{G}_{1}$ phase cells in the control group increased from $0.73 \pm 0.09$ to $90.01 \pm 3.17 \%$ following $48 \mathrm{~h}$ of treatment with linalool $(\mathrm{P}<0.01$; Fig. 1E).

Linalool inhibits T-ALL cell survival with involvement of the MAPK signaling pathway. RNA sequencing demonstrated that 3,512 genes were significantly differentially expressed before and after treatment with $30 \mu \mathrm{M}$ linalool for $9 \mathrm{~h}$. Enrichment of mRNAs in the regulatory network was assessed by analysis of KEGG pathways and it was found that the MAPK signaling pathway (the - $\log _{10}$ value was 10.62 ) was significantly involved in the effect of linalool treatment on Jurkat cells (Fig. 2). Subsequently, a GO analysis was conducted to determine the functional roles of these differentially expressed genes. The differently expressed genes enriched in GO terms were associated with 'protein binding', 'regulation of biological process' and 'response to stimulus' (the $-\log _{10}$ value were $36.2,38.6$, and 38.5, respectively) (Fig. S1). A distinct set of upregulated genes associated with the MAPK signaling pathway was identified using heatmap (Fig. 3).

To verify the RNA sequencing results, the mRNA levels of GADD45A and HSPB1 (HSP27) which are components of the MAPK signaling pathway (30) were assessed by RT-qPCR in Jurkat cells. Consistent with the sequencing results, GADD45A mRNA levels $(1.02 \pm 0.02 ; 1.56 \pm 0.28 ; 2.63 \pm 0.41$ and $4.87 \pm 0.70)$ and HSP27 mRNA levels $(1.00 \pm 0.01,2.04 \pm 0.51,3.65 \pm 0.74$, and $4.48 \pm 0.82)$ were significantly upregulated in a time-dependent manner $(0,6,12$ or $24 \mathrm{~h})$ following treatment with $30 \mu \mathrm{M}$ linalool $(\mathrm{P}<0.05$; Fig. 4A and $\mathrm{B})$. 


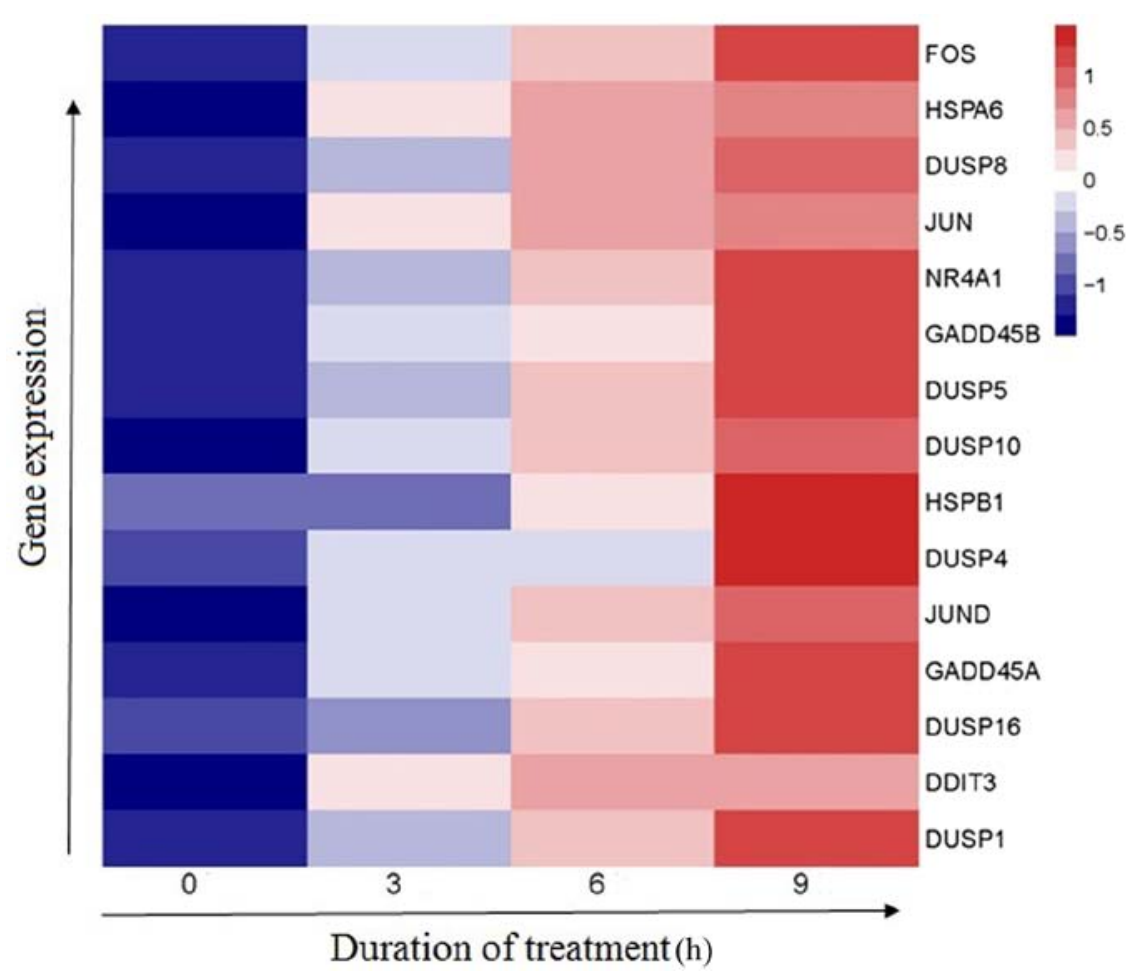

Figure 3. Heatmap of gene expression of the MAPK signaling pathway. Jurkat cells were treated with $30 \mu \mathrm{M}$ linalool for 3, 6 and 9 h. RNA sequencing was performed on the Illumina HiSeq 2500 platform, and heatmap was generated using R language version 3.4.4. Heatmap demonstrating a distinct set of upregulated genes associated with the MAPK signaling pathway. Red and blue colors depict high and low gene expression levels, respectively. Levels were scaled based on expression values that have been mean-centered to 0 . The experiments were repeated three times.

Linalool inhibits T-ALL cell survival with the involvement of p-ERK suppression and $p$-JNK activation. Jurkat cells were treated with $30 \mu \mathrm{M}$ linalool at $0,6,12$ or $24 \mathrm{~h}$. Western blot analysis demonstrated that $\mathrm{p}-\mathrm{JNK}$ and GADD45A protein expression were upregulated in a time-dependent manner, while p-ERK protein expression was downregulated in a time-dependent manner (Fig. 4C and D). ERK, p38, p-p38 and JNK protein expression showed no obvious differences following treatment with linalool (Fig. 4C and D). The relative ratio of cleaved caspase-3/total caspase-3 and cleaved PARP/total PARP was significantly upregulated in a time-dependent manner after treatment with $30 \mu \mathrm{M}$ linalool (Fig. 4E and F). In addition, the ratio of p-JNK protein/total JNK protein $(0.69 \pm 0.02,0.70 \pm 0.02,0.73 \pm 0.01$ and $0.85 \pm 0.02)$ demonstrated an upward trend in a time-dependent manner following treatment with $30 \mu \mathrm{M}$ linalool with $24 \mathrm{~h}$ treatment demonstrating significant difference compared to the other time points tested $(\mathrm{P}<0.05$; Fig. $4 \mathrm{G})$. Conversely, the ratio of p-ERK protein/total ERK protein $(0.97 \pm 0.02,0.84 \pm 0.01$, $0.82 \pm 0.01$ and $0.79 \pm 0.01$ ) demonstrated a downward trend in a time-dependent manner where the ratio at $0 \mathrm{~h}$ was significantly higher compared with 6,12 and $24 \mathrm{~h}(\mathrm{P}<0.05$; Fig. 4H) indicating a suppression of $\mathrm{p}$-ERK protein. For the ratio of p-p38 protein/total p38 protein, no significant difference was found after treatment with $30 \mu \mathrm{M}$ linalool at $0 \mathrm{~h}(0.97 \pm 0.02)$, $6 \mathrm{~h}(0.97 \pm 0.01), 12 \mathrm{~h}(0.95 \pm 0.01)$ or $24 \mathrm{~h}(0.94 \pm 0.01)$ (Fig. 5A).

To further determine the role of ERK, JNK and p38 in linalool-induced Jurkat cell inhibition and apoptosis, specific inhibitors were used for $1 \mathrm{~h}$ before treatment with $30 \mu \mathrm{M}$ linalool for $9 \mathrm{~h}$. With the addition of $10 \mu \mathrm{mol} / 1$ ERK inhibitor PD98059, cell viability was significantly reduced compared with the use of $30 \mu \mathrm{M}$ linalool alone (5.57 \pm 2.12 vs. $38.70 \pm 3.24$; $\mathrm{P}<0.001$; Fig. 5B) and the number of apoptotic cells was significantly increased compared with the use of $30 \mu \mathrm{M}$ linalool alone ( $83.0 \pm 4.03$ vs. $46.72 \pm 3.15 ; \mathrm{P}<0.001 ;$ Fig. $5 \mathrm{C}$ ). In addition, the addition of $20 \mu \mathrm{mol} / 1 \mathrm{JNK}$ inhibitor SP600125 compared with the use of $30 \mu \mathrm{M}$ linalool alone, significantly reversed the linalool-mediated inhibition of Jurkat cell viability $(55.33 \pm 3.35$ vs. $38.70 \pm 3.24$; $\mathrm{P}<0.01$; Fig. $5 \mathrm{~B})$ and apoptosis $(24.9 \pm 3.47$ vs. $46.72 \pm 3.15$; $\mathrm{P}<0.01$; Fig. $5 \mathrm{C}$ ). However, the addition of $10 \mu \mathrm{mol} / 1 \mathrm{p} 38$ inhibitor SB203580 demonstrated no significant effect on cell viability and apoptosis compared to the use of $30 \mu \mathrm{M}$ linalool alone ( $>>0.05$; Fig. 5B and $\mathrm{C}$ ). The aforementioned results demonstrated that the JNK inhibitor SP600125 significantly reversed the linalool-mediated growth inhibition and apoptosis, the ERK1/2-selective inhibitor PD98059 enhanced the linalool-induced growth inhibition and apoptosis and the inhibition of p38 activity with SB203580 resulted in a very modest increase in growth inhibition and apoptosis.

\section{Discussion}

Although, the effects of treatments for T-ALL have dramatically improved over the years, the prognosis of T-ALL is still poor $(1,2)$. There is a pressing need for the development of more effective and safer treatments (2-4). Linalool can inhibit the growth of a variety of tumor cells, including hepatocellular carcinoma, breast cancer, small cell carcinoma and malignant melanoma (9-15). In the present study, linalool inhibited the viability of 4 human T-ALL cell lines in a dose-dependent manner. The $\mathrm{IC}_{50}$ at $48 \mathrm{~h}$ of Jurkat cells was higher compared with that of H9, Molt-4 or Raji cells, hence Jurkat cells were 


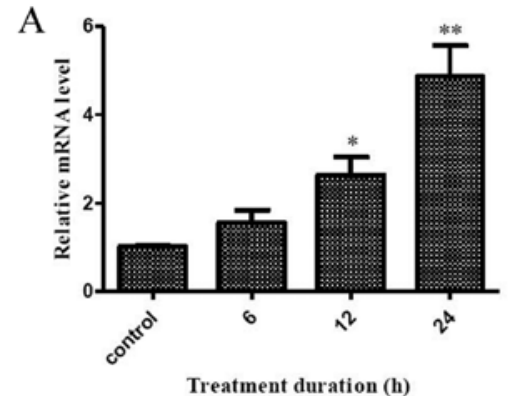

GADD45A
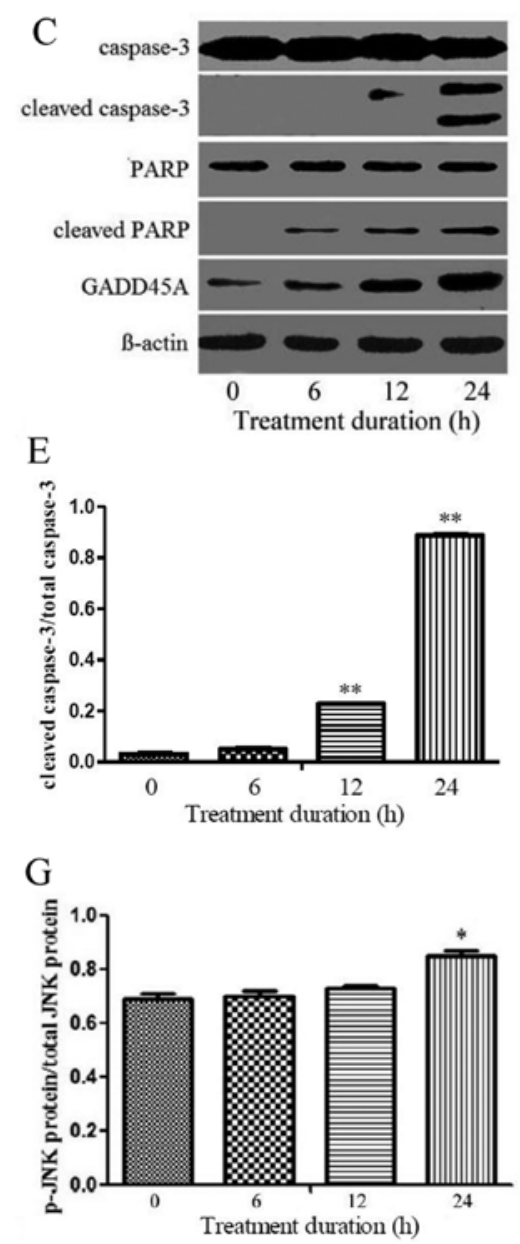

B

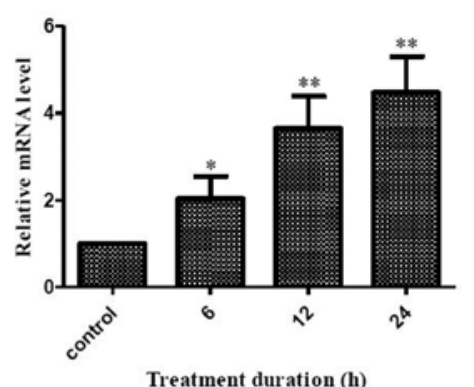

HSP27

D

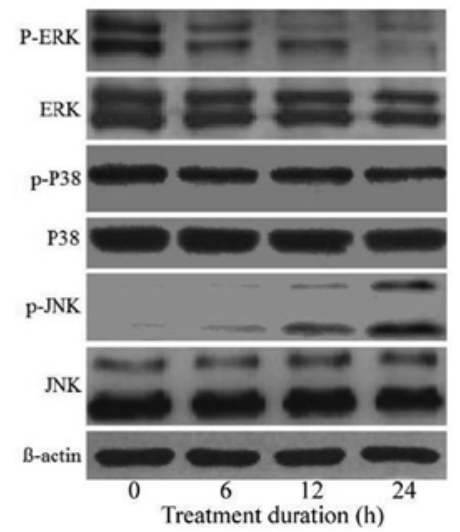

F

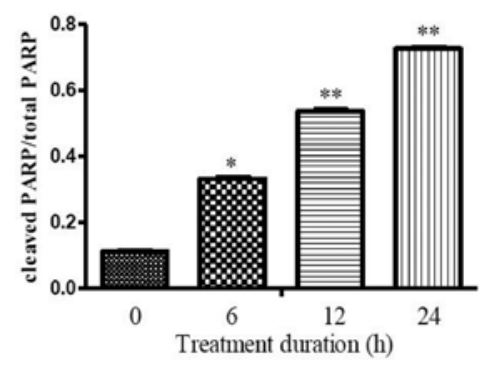

$\mathrm{H}$

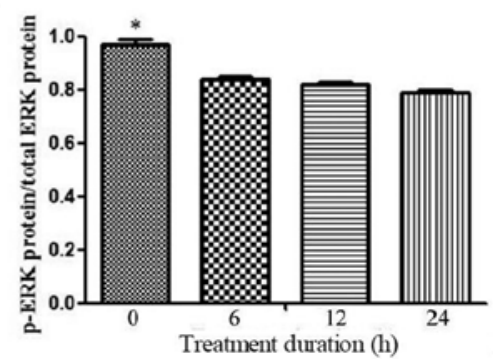

Figure 4. Linalool inhibited T-ALL cells survival by p-ERK suppression and p-JNK activation. (A and B) RT-qPCR results demonstrating that GADD45A and HSP27 mRNA levels were significantly upregulated in a time-dependent manner after treatment with $30 \mu \mathrm{M}$ linalool, $\mathrm{P}<0.05$, ${ }^{* *} \mathrm{P}<0.01$ compared with control group. (C and D) Western blotting results following $30 \mu \mathrm{M}$ linalool treatments of Jurkat cells. p-JNK, GADD45A, cleaved caspase-3 and cleaved PARP protein expression were upregulated in a time-dependent manner, while p-ERK protein expression was downregulated. In addition, ERK, p38, p-P38 and JNK protein expression showed no obvious differences compared to the $0 \mathrm{~h}$ group. (E and F) The relative ratios of cleaved PARP/total PARP and cleaved caspase-3/total caspase-3 were significantly upregulated in a time-dependent manner after treatment with $30 \mu \mathrm{M}$ linalool compared with $0 \mathrm{~h}$ group $\left({ }^{*} \mathrm{P}<0.05\right)$. ( $\left.\mathrm{G}\right)$ The ratio of $\mathrm{p}$-JNK protein/total JNK protein demonstrated an upward trend in a time-dependent manner and the corresponding ratio at $24 \mathrm{~h}$ was obviously higher than that at 0,6 and $12 \mathrm{~h}$. (H) The ratio of p-ERK protein/total ERK protein demonstrated a downward trend in a time-dependent manner, the corresponding ratio at $0 \mathrm{~h}$ was significantly higher compared with that at 6,12 , and $24 \mathrm{~h}(\mathrm{P}<0.05)$. The experiments were repeated at least three times. T-ALL, T cell acute lymphoblastic leukaemia; GADD45A, Growth Arrest And DNA Damage Inducible $\alpha$; PARP, Poly (ADP-ribose) polymerase; p, phosphorylated; RT-q, reverse-transcription quantitative; HSP 27, heat shock protein 27.

chosen in the present study for the subsequent analysis. In addition, as a normal cell line was not available PBMCs were chosen for comparison in the present study. The viability of PBMCs from normal individuals was unaffected when the cells were treated with $30 \mu \mathrm{M}$ linalool. Annexin V-FITC/PI analysis conducted in the present study revealed that linalool inhibits the viability of Jurkat cells by inducing the apoptosis of leukemia cells, which was also verified by morphological analysis.

Cell cycle control is a major event in cellular division and the disruption of the normal cell cycle serves an important role 

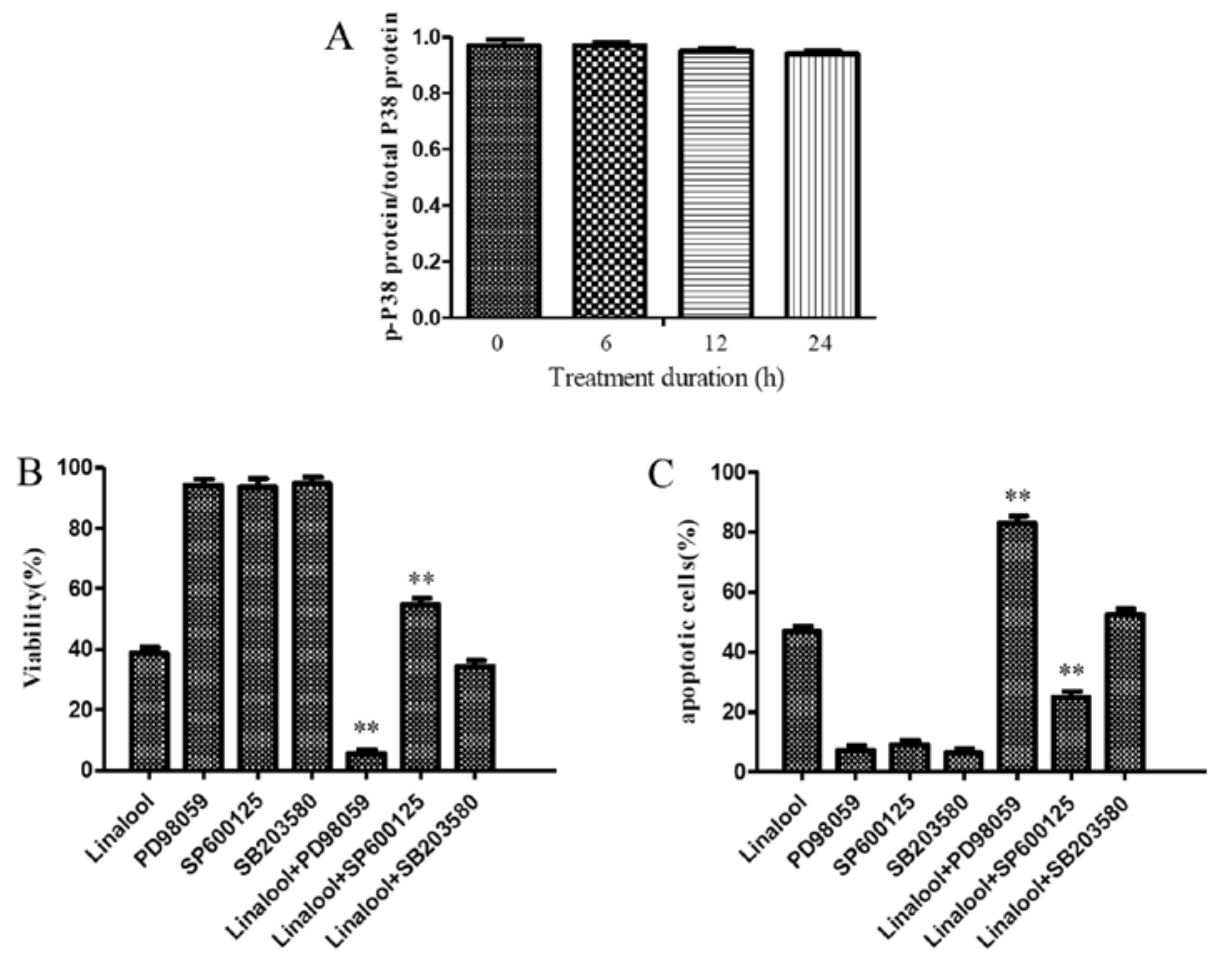

Figure 5. ERK inhibitor PD98059 enhanced the inhibition of T-ALL cells survival, while JNK inhibitor SP600125 reversed linalool-mediated growth inhibition and apoptosis. (A) For the ratio of p-p38 protein/total p38 protein, no significant difference was found after treatment with $30 \mu \mathrm{M}$ linalool at $0 \mathrm{~h}$ $(0.97 \pm 0.02), 6 \mathrm{~h}(0.97 \pm 0.01), 12 \mathrm{~h}(0.95 \pm 0.01)$ or $24 \mathrm{~h}(0.94 \pm 0.01)$. (B) Addition of $10 \mu \mathrm{mol} / 1$ ERK inhibitor PD 98059 significantly reduced cell viability while the addition of $20 \mu \mathrm{mol} / 1 \mathrm{JNK}$ inhibitor SP600125 significantly reversed linalool-mediated growth inhibition and the addition of $10 \mu \mathrm{mol} / 1 \mathrm{p} 38$ inhibitor SB203580 had no obvious effect on the cell viability compared with $30 \mu \mathrm{M}$ linalool treatment alone. (C) The addition of $10 \mu \mathrm{mol} / 1$ ERK inhibitor PD98059 significantly increased the cell apoptosis, the addition of $20 \mu \mathrm{mol} / 1 \mathrm{JNK}$ inhibitor SP600125 significantly reversed linalool-mediated apoptosis and the addition of $10 \mu \mathrm{mol} / 1 \mathrm{p} 38$ inhibitor SB203580 had no obvious changes on the cell apoptosis compared with $30 \mu \mathrm{M}$ Linalool treatment alone. All the experiments were repeated at least three times. ${ }^{* *} \mathrm{P}<0.01$ compared with $30 \mu \mathrm{M}$ linalool treatment group.

in the development of tumors (31). A large number of antitumor natural compounds, such as baicalin and homoharringtonine, have demonstrated to induce cell death and apoptosis in close association with cell cycle arrest at the $\mathrm{G}_{1}$ phase $(31,32)$. Notably, the present study demonstrated that Jurkat cells treated with linalool had reduced cell accumulation at the $\mathrm{G}_{0} / \mathrm{G}_{1}$ phase, which contains numerous non-proliferating leukaemia cells (33). The findings of the present study indicate that linalool may affect proliferating and non-proliferating T-ALL cells. The latter are highly related to traditional chemotherapeutic drug resistance and tumor recurrence $(3,4)$. The effect of linalool on non-proliferating T-ALL cells should be investigated in future studies.

The development of next-generation sequencing technology has provided new tools for exploring the differential gene expression of tumors before and after treatment (34). In the present study, the HiSeq X Series sequencing platform was used to perform RNA sequencing analysis on Jurkat cells before and after treatment with linalool. The present study identified 3,512 genes were statistically differentially expressed before and after treatment with $30 \mu \mathrm{M}$ linalool for $9 \mathrm{~h}$. In the present study, KEGG pathway analysis and Gene Ontology enrichment analysis were conducted. The KEGG pathways analysis demonstrated that the MAPK signaling pathway is significantly involved in the effect of linalool treatment on Jurkat cells and the GO enrichment analysis demonstrated that the differently expressed genes enriched in GO terms were associated with 'protein binding', 'regulation of biological process' and 'response to stimulus'.
The MAPK signaling pathways are known to function as crucial components of cell proliferation and apoptosis in tumor cells and have been identified as chemotherapeutic targets for sensitizing tumor cells to apoptosis (35). In the present study, RT-qPCR was performed to confirm the RNA sequencing results in Jurkat cells and the effect of linalool treatment on the mRNA levels of GADD45A and HSP27 from the MAPK signaling pathway was assessed. Consistent with the RNA sequencing results, exposure to linalool resulted in a significant increase in the mRNA levels of GADD45A and HSP27. The findings of the present study revealed that linalool inhibits T-ALL cells survival through the involvement of the MAPK signaling pathway.

MAPKs in mammals include JNK, p38 MAPK, and ERK (36). Western blotting conducted in the present study demonstrated that the $\mathrm{p}-\mathrm{JNK}$ protein expression level significantly increased following linalool treatment and inhibition of JNK activity by the JNK inhibitor SP600125 significantly reversed the linalool-mediated growth inhibition and apoptosis in Jurkat cells. In addition, linalool treatment exerted a significant inhibitory effect on p-ERK $1 / 2$ protein expression and the ERK1/2-selective inhibitor PD98059 enhanced the linalool-induced growth inhibition and apoptosis in Jurkat cells. However, p-p38 protein expression and p38 mRNA levels were not obviously different following linalool treatment and the inhibition of p38 activity with SB203580 resulted in a very modest increase in growth inhibition and apoptosis. Taken together, the findings of the present study indicated that the 
JNK and ERK pathways, but not the p38 pathway are involved in linalool-induced apoptosis of Jurkat cells.

In conclusion, the present study revealed that linalool can preferentially inhibit the viability of T-ALL cells without any significant toxicity in PBMCs from normal individuals. In addition, it was demonstrated that linalool inhibits T-ALL cell survival with involvement of MAPK signaling pathways, JNK activation and ERK inhibition, which serve functional roles in apoptosis induction. Linalool may be developed as a novel anti T-ALL leukaemia agent. Future animal experiments should be conducted for the comparison of the effect and safety of linalool with other traditional chemotherapy drugs.

\section{Acknowledgements}

Not applicable.

\section{Funding}

This work was supported by a grant from the National Natural Science Foundation of China (grant no. 81400107).

\section{Availability of data and materials}

All data generated or analysed during this study are included in this published article.

\section{Authors' contributions}

$\mathrm{XZ}$ conceived and designed the study. XG, BW and XL performed the experiments. LY prepared the figures and analysed the data. XG wrote the manuscript. All authors have read and approved the final manuscript.

\section{Ethics approval and consent to participate}

This study was approved by the Ethics Committee of The Second Affiliated Hospital, School of medicine, Zhejiang University (Hangzhou, China; approval number:, IR2020001187) according to the guidelines of the Declaration of Helsinki. A written consent form was obtained from all the participating healthy donors.

\section{Patient consent for publication}

Not applicable.

\section{Competing interests}

The authors declare that they have no competing interests.

\section{References}

1. Swerdlow SH, Campo E, Pileri SA, Harris NL, Stein H, Siebert R, Advani R, Ghielmini M, Salles GA, Zelenetz AD and Jaffe ES: The 2016 revision of the world health organization classification of lymphoid neoplasms. Blood 127: 2375-2390, 2016.

2. Gascoyne RD, Campo E, Jaffe ES, Chan WC, Chan JK, Rosenwald A, Stein A and Swerdlow SH: Diffuse large B-cell lymphoma, not otherwise specified. In: World health organization classification of haematopoietic and lymphoid tissues of tumors. 4th edition. IARC Press, Lyon, France, pp 291-297, 2016.
3. Kato K, Uike N, Wake A, Yoshimitsu M, Tobai T, Sawayama Y, Takatsuka Y, Fukuda T, Uchida N, Eto T, et al: The outcome and characteristics of patients with relapsed adult $\mathrm{T}$ cell leukemia/lymphoma after allogeneic hematopoietic stem cell transplantation. Hematol Oncol 37: 54-61, 2019.

4. Vadillo E, Dorantes-Acosta E, Pelayo R and Schnoor M: T cell acute lymphoblastic leukemia (T-ALL): New insights into the cellularorigins and infiltration mechanisms common and unique among hematologic malignancies. Blood Rev 32: 36-51, 2018.

5. Thol $\mathrm{F}$ and Ganser A: Treatment of relapsed acute myeloid leukemia. Curr Treat Options Oncol 21: 66, 2020.

6. Vázquez-Sánchez D, Galvão JA, Mazine MR, Gloria EM and Oetterer M: Control of staphylococcus aureus biofilms by the application of single and combined treatments based in plant essential oils. Int J Food Microbiol 286: 128-138, 2018.

7. Burdock GA and Carabin IG: Safety assessment of coriander (Coriandrum sativum L.) essential oil as a food ingredient. Food Chem Toxicol 47: 22-34, 2009.

8. Elliott JF, Ramzy A, Nilsson U, Moffat W and Suzuki K: Severe intractable eyelid dermatitis probably caused by exposure to hydroperoxides of linalool in a heavily fragranced shampoo. Contact Dermatitis 76: 114-115, 2017.

9. Ramzi A, Ahmadi H, Sadiktsis I and Nilsson U: A two-dimensional non-comprehensive reversed/normal phase high-performance liquid chromatography/tandem mass spectrometry system for determination of limonene and linalool hydroperoxides. J Chromatogr A 1566: 102-110, 2018.

10. Jabir MS, Taha AA, Sahib UI, Taqi ZJ, Al-Shammari AM and Salman AS: Novel of nano delivery system for linalool loaded on gold nanoparticles conjugated with CALNN peptide for application in drug uptake and induction of cell death on breast cancer cell line. Mater Sci Eng C Mater Biol Appl 94: 949-964, 2019.

11. Elansary HO, Abdelgaleil SA, Mahmoud EA, Yessoufou K, Elhindi K and El-Hendawy S: Effective antioxidant, antimicrobial and anticancer activities of essential oils of horticultural aromatic crops in northern Egypt. BMC Complement Altern Med 18: 214, 2018

12. Sakurai K, Tomiyama K, Yaguchi Y and Asakawa Y: Characteristic odor of the Japanese liverwort (Leptolejeunea elliptica). J Oleo Sci 69: 767-770, 2020.

13. Kubatka P, Kello M, Kajo K, Samec M, Jasek K, Vybohova D, Uramova S, Liskova A, Sadlonova V, Koklesova L, et al: Chemopreventive and therapeutic efficacy of cinnamomum zeylanicum L. Bark in experimental breast carcinoma: Mechanistic in vivo and in vitro analyses. Molecules 25: 1399, 2020.

14. Chang MY, Shieh DE, Chen CC, Yeh CS and Dong HP: Linalool induces cell cycle arrest and apoptosis in leukemia cells and cervical cancer cells through CDKIs. Int J Mol Sci 16: 28169-28179, 2015.

15. Miyashita M and Sadzuka Y: Effect of linalool as a component of humulus lupulus on doxorubicin-induced antitumor activity. Food Chem Toxicol 53: 174-179, 2013.

16. He X, Zhu Y, Lin YC, Li M, Du J, Dong H, Sun J, Zhu L, Wang H, Ding Z, et al: PRMT1-mediated FLT3 arginine methylation promotes maintenance of FLT3-ITD+acute myeloid leukemia. Blood 134: 548-560, 2019.

17. Maeda H, Yamazaki M and Katagata Y: Kuromoji (Lindera umbellata) essential oil-induced apoptosis and differentiation in human leukemiaHL-60 cells. Exp Ther Med 3: 49-52, 2012.

18. Saab AM, Tundis R, Loizzo MR, Lampronti I, Borgatti M, Gambari R, Menichini F, Esseily F and Menichini F: Antioxidant and antiproliferative activity of Laurus nobilis L. (Lauraceae) leaves and seeds essential oils against K562 human chronic myelogenous leukaemia cells. Nat Prod Res 26: 1741-1745, 2012.

19. Gu Y, Ting Z, Qiu X, Zhang X, Gan X, Fang Y, Xu X and Xu R: Linalool preferentially induces robust apoptosis of a variety of leukemia cells via upregulating p53 and cyclin-dependent kinase inhibitors. Toxicology 268: 19-24, 2010.

20. Souza-Junior FJ, Luz-Moraes D, Pereira FS, Barros MA, Fernandes LM, Queiroz LY, Maia CF, Maia JG and Fontes-Junior EA: Aniba canelilla (Kunth) mez (Lauraceae): A review of ethnobotany, phytochemical, antioxidant, anti-inflammatory, cardiovascular, and neurological properties. Front Pharmacol 11: 699, 2020

21. Li CJ: Flow cytometry analysis of cell cycle and specific cell synchronization with butyrate. Methods Mol Biol 1524: 149-159, 2017.

22. Langmead B and Salzberg SL: Fast gapped-read alignment with bowtie 2. Nat Methods 9: 357-359, 2012. 
23. Livak KJ and Schmittgen TD: Analysis of relative gene expression data using real-time quantitative PCR and the 2(-Delta Delta C(T)) method. Methods 25: 402-408, 2001.

24. Li B and Dewey CN: RSEM: Accurate transcript quantification from RNA-Seq data with or without a reference genome. BMC Bioinformatics 12: 323, 2011.

25. Li JJ, Wang W, Wang XQ, He Y, Wang SS and Yan YX: A novel strategy of identifying circRNA biomarkers in cardiovascular disease by meta-analysis. J Cell Physiol 234: 21601-21612, 2019.

26. Tang YL, Fang LJ, Zhong LY, Jiang J, Dong XY and Feng Z: Hub genes and key pathways of traumatic brain injury: Bioinformatics analysis and in vivo validation. Neural Regen Res 15: 2262-2269, 2020.

27. Wu Y, Xia L, Guo Q, Zhu J, Deng Y and Wu X: Identification of chemoresistance-associated key genes and pathways in high-grade serous ovarian cancer by bioinformatics analyses. Cancer Manag Res 12: 5213-5223, 2020.

28. Gao M, Zhang S, Luo C, He X, Wei S, Jiang W, He F, Lin Z, Yan M and Dong W: Transcriptome analysis of starch and sucrose metabolism across bulb development in Sagittaria sagittifolia. Gene 649: 99-112, 2018.

29. Gu Y, Zhang J, Ma X, Kim BW, Wang H, Li J, Pan Y, Xu Y, Ding L, Yang L, et al: Stabilization of the c-myc protein by CAMKII $\gamma$ promotes T cell lymphoma. CancerCell 2: 115-128, 2017.

30. Yang L, Zhang C, Chen J, Zhang S, Pan G, Xin Y, Lin L and You Z: Shenmai injection suppresses multidrug resistance in MCF-7/ADR cells through the MAPK/NF- $\kappa \mathrm{B}$ signalling pathway. Pharm Biol 58: 276-285, 2020.
31. Baell JB, Leaver DJ, Hermans SJ, Kelly GL, Brennan MS, Downer NL, Nguyen N, Wichmann J, McRae HM, Yang Y, et al: Inhibitors of histone acetyltransferases KAT6A/B induce senescence and arrest tumor growth. Nature 560: 253-257, 2018.

32. Gao Y, Liu H, Wang H, Hu H, He H, Gu N, Han X, Guo Q, Liu D, Cui S, et al: Baicalin inhibits breast cancer development via inhibiting IKB kinase activation in vitro and in vivo. Int J Oncol 53: 2727-2736, 2018

33. Kong Y, Zhao S, Tian H and Hai Y: GAS2 promotes cell proliferation and invasion and suppresses apoptosis in pediatric T-cell acute lymphoblastic leukemia and activates wnt/ $\beta$-catenin pathway. Onco Targets Ther 13: 1099-1108, 2020.

34. Rheinbay E, Parasuraman P, Grimsby J, Tiao G, Engreitz JM, Kim J, Lawrence MS, Taylor-Weiner A, Rodriguez-Cuevas S, Rosenberg M, et al: Recurrent and functional regulatory mutations in breast cancer. Nature 547: 55-60, 2017.

35. Athuluri-Divakar SK, Vasquez-Del Carpio R, Dutta K, Baker SJ, Cosenza SC, Basu I, Gupta YK, Reddy MV, Ueno L, Hart JR, et al: A small molecule RAS-mimetic disrupts RAS association with effector proteins to block signaling. Cell 165: 643-655, 2016.

36. Johannessen CM, Johnson LA, Piccioni F, Townes A, Frederick DT, Donahue MK, Narayan R, Flaherty KT, Wargo JA, Root DE and Garraway LA: A melanocyte lineage program confers resistance to MAP kinase pathway inhibition. Nature 504: 138-142, 2013.

This work is licensed under a Creative Commons Attribution-NonCommercial-NoDerivatives 4.0 International (CC BY-NC-ND 4.0) License. 